\title{
Plasticity of Lateral Root Branching in Maize
}

\author{
Peng $Y u^{1 *}$, Frank Hochholdinger ${ }^{1}$ and Chunjian $L i^{2 *}$ \\ ${ }^{1}$ Crop Functional Genomics, Institute of Crop Science and Resource Conservation (INRES), University of Bonn, Bonn, \\ Germany, ${ }^{2}$ Department of Plant Nutrition, College of Resources and Environmental Science, China Agricultural University, \\ Beijing, China
}

Extensively branched root systems can efficiently capture soil resources by increasing their absorbing surface in soil. Lateral roots are the roots formed from pericycle cells of other roots that can be of any type. As a consequence, lateral roots provide a higher surface to volume ratio and are important for water and nutrients acquisition. Discoveries from recent studies have started to shed light on how plant root systems respond to environmental changes in order to improve capture of soil resources. In this Mini Review, we will mainly focus on the spatial distribution of lateral roots of maize and their developmental plasticity in response to the availability of water and nutrients.

\section{OPEN ACCESS}

Edited by:

Joseph G. Dubrovsky,

National Autonomous University of

Mexico, Mexico

Reviewed by:

Jonathan Lynch,

Pennsylvania State University,

United States

Ricardo Fabiano Hettwer Giehl, Leibniz-Institut für Pflanzengenetik und Kulturpflanzenforschung (IPK),

Germany

${ }^{*}$ Correspondence: Peng Yu

yupeng@uni-bonn.de

Chunjian Li

lichj@cau.edu.cn

Specialty section:

This article was submitted to Plant Development and EvoDevo,

a section of the journal

Frontiers in Plant Science

Received: 28 November 2018 Accepted: 08 March 2019

Published: 29 March 2019

Citation:

Yu P, Hochholdinger F and Li C (2019) Plasticity of Lateral Root Branching in Maize.

Front. Plant Sci. 10:363.

doi: 10.3389/fp/s.2019.00363
Keywords: maize, lateral root, plasticity, nitrate, water

\section{INTRODUCTION}

Maize forms a structurally and functionally complex root system composed of different root types (Hochholdinger et al., 2017) to efficiently acquire water and nutrients (Lynch, 2013) and to tolerate biotic and abiotic stresses (Lynch et al., 2014). Lateral roots of different orders are the most eminent root type for nutrient and water uptake from soil because of their high surface to volume ratio (Rogers and Benfey, 2015). Compared to other root types, lateral roots display the highest developmental plasticity when exposed to unfavorable environmental conditions (Yu et al., 2014a, 2016a). The formation and spatial distribution of lateral roots, e.g., lateral root branching is the most important factor governing root system architecture and soil exploration in plants (Atkinson et al., 2014). Thus, genotypes with lateral root defects display a strong inhibition of nutrient uptake and biomass production in crops (Yu et al., 2016a). The molecular mechanisms and hormonal crosstalk involved in lateral root formation and positioning has been extensively studied in the model plant Arabidopsis thaliana (Möller et al., 2017; Ötvös and Benková, 2017). Genetic and molecular control of lateral root initiation and formation in maize has been summarized in the recent review (Yu et al., 2016a). In this Mini Review, we provide an update on the molecular mechanisms involved in the lateral root branching response to environmental cues such as nutrients and water in maize.

\section{ARCHITECTURAL RESPONSES OF LATERAL ROOTS TO THE AVAILABILITY OF SOIL RESOURCES}

The significantly higher surface area of the lateral roots compared to their parental roots is a major determinant that is instrumental for water uptake in maize (Ahmed et al., 2016). Lateral roots are efficient in the short-distance exploitation and transport of water from soil to the vasculature in young and adult maize plants (Ahmed et al., 2016, 2018). 
Genotypic differences in lateral root branching and their vertical distribution along the root system are a measure for drought tolerance in soil (Hund et al., 2009). Maize genotypes with reduced lateral root branching have been shown to be highly tolerant against drought under both greenhouse and field conditions (Zhan et al., 2015). A possible explanation for this observation is the negative correlation between lateral root branching and axial root elongation (Lynch, 2015). In maize, distinct orders of lateral roots make up the majority of total length of the root system (Lynch, 2013). Different plant species display distinct responses to nitrogen and phosphorus starvation with respect to their lateral root branching patterns, although dicot and monocot plants show similar patterns of lateral root spacing along the primary root under optimal conditions (Chen et al., 2018). The optimal branching density of lateral roots in maize has been predicted by the functional-structural model SimRoot based on the observation that nutrient acquisition is proportional to the spatial availability and mobility of resources in the soil profile (Postma et al., 2014). Genotypes with sparsely distributed and long lateral roots are optimal for nitrate acquisition, whereas genotypes with densely spaced and short lateral roots are optimal for phosphorus acquisition in maize (Postma et al., 2014). Recent results in maize have indicated that genotypes with higher lateral root branching density display significantly increased phosphorus acquisition under phosphorus-deficient conditions (Liu et al., 2013; Jia et al., 2018). By contrast, maize genotypes with few and long lateral roots are more competent for nitrogen uptake than genotypes with many and short lateral roots under suboptimal nitrogen concentrations in soil (Zhan and Lynch, 2015). Thus, availability of soil nutrients and water determines compensatory growth and patterning of lateral roots along the parental root axes.

\section{LATERAL ROOT BRANCHING IN RESPONSE TO PATCHY SOIL RESOURCES}

Lateral root branching patterns reflect the uneven distribution of water and nutrients in soil (Robinson, 1994). Plants adapt to heterogeneous water conditions by altering their lateral root branching in contact with water by using "hydropatterning" response (Bao et al., 2014; Robbins and Dinneny, 2018). Highresolution non-invasive microcomputed tomography imaging has revealed that the formation and patterning of lateral roots is highly responsive to local water availability in A. thaliana and crop species (Bao et al., 2014; Robbins and Dinneny, 2015; Orman-Ligeza et al., 2018). Xerobranching, describing the repression of lateral root branching when root tips are not in contact with wet soil, suggests that abscisic acid is involved as key signal regulating branches of lateral roots in their local microenvironment (Orman-Ligeza et al., 2018). For hydropatterning, high availability of water results in the induction of auxin biosynthesis and transport, independent of endogenous abscisic acid signals (Bao et al., 2014; Figure 1A). A recent study with $A$. thaliana demonstrated that hydropatterning is dependent on SUMO-mediated posttranslational regulation of auxin signaling pathway (ARF7/IAA3) controlling lateral root branching pattern in response to water availability (OrosaPuente et al., 2018; Figure 1A). ARF7 transcription factor induces asymmetric expression of its target gene LATERAL ORGAN BOUNDARIES (LOB) domain 16 (LBD16) in lateral root founder cells (Orosa-Puente et al., 2018; Figure 1A). Future work will be necessary to understand how the water and nutrient signals are integrated to regulate lateral root branching in response to local water/nutrients availability (Giehl and von Wirén, 2018). Through a combination of empirical and mathematical-modeling approaches in maize, it has been shown a central role of tissue growth and developmental competence, which is necessary to sustain the normal hydropatterning, although the molecular mechanism is unknown in crop plants (Robbins and Dinneny, 2018). This result implies that the water requirement for fast developing tissue is an important contribution process on water perception and developmental reprogramming during the postembryonic root development.

Lateral root formation in response to systemic and local nitrate signaling has been recently summarized in A. thaliana (Sun et al., 2017). A series of experiments have demonstrated that local nitrate supply can considerably stimulate lateral root production also in crops, such as maize (Wang et al., 2004; Guo et al., 2005; Liu et al., 2008, 2010), rice (Huang et al., 2015), barley (Drew et al., 1973), and wheat (Hackett, 1972). Hydroponics allows local nutrient application under well-controlled conditions, which can also avoid influences of other factors such as physical properties of soil and microbes. Local application of nutrients in hydroponics includes two strategies: one is the vertical split system that the middle part of the root was supplied with high nutrients along the longitudinal axis (Drew et al., 1973); another strategy is horizontal split system that the axial roots are separated into different compartments or rhizoslides with diverse nutrient levels (Yu et al., 2014b; Dina in't Zandt et al., 2015). The complex nature of the root system of maize plants makes split-root experiments challenging. Most common ways to carry out such experiments is by placing the primary root into one compartment and the other root types are placed into the other one (Yu et al., 2014b, 2015, 2016b) or the crown roots are equally separated and cultured in different compartments after removing the primary and seminal roots (Wang et al., 2004; Guo et al., 2005; Liu et al., 2008, 2010). Vertical hydroponics experiments by Drew and his colleagues demonstrated that lateral root formation in barley depends on the dose and type of nutrient application (reviewed in Yu et al., 2014a). Both length and density of lateral roots are significantly induced by local high nitrate (control: $0.01 \mathrm{mM}$; high nitrate $1 \mathrm{mM}$ ) in barley seedlings (Drew et al., 1973). By contrast, only elongation of the lateral roots on primary root is induced in maize seedlings split supplied by local high nitrate (control: $0.5 \mathrm{mM}$; high nitrate $4 \mathrm{mM}$ ) in 7-day-old maize seedlings grown in the left-right hydroponic system (Yu et al., 2014b). This is consistent with the lateral root formation from the crown roots of maize, 

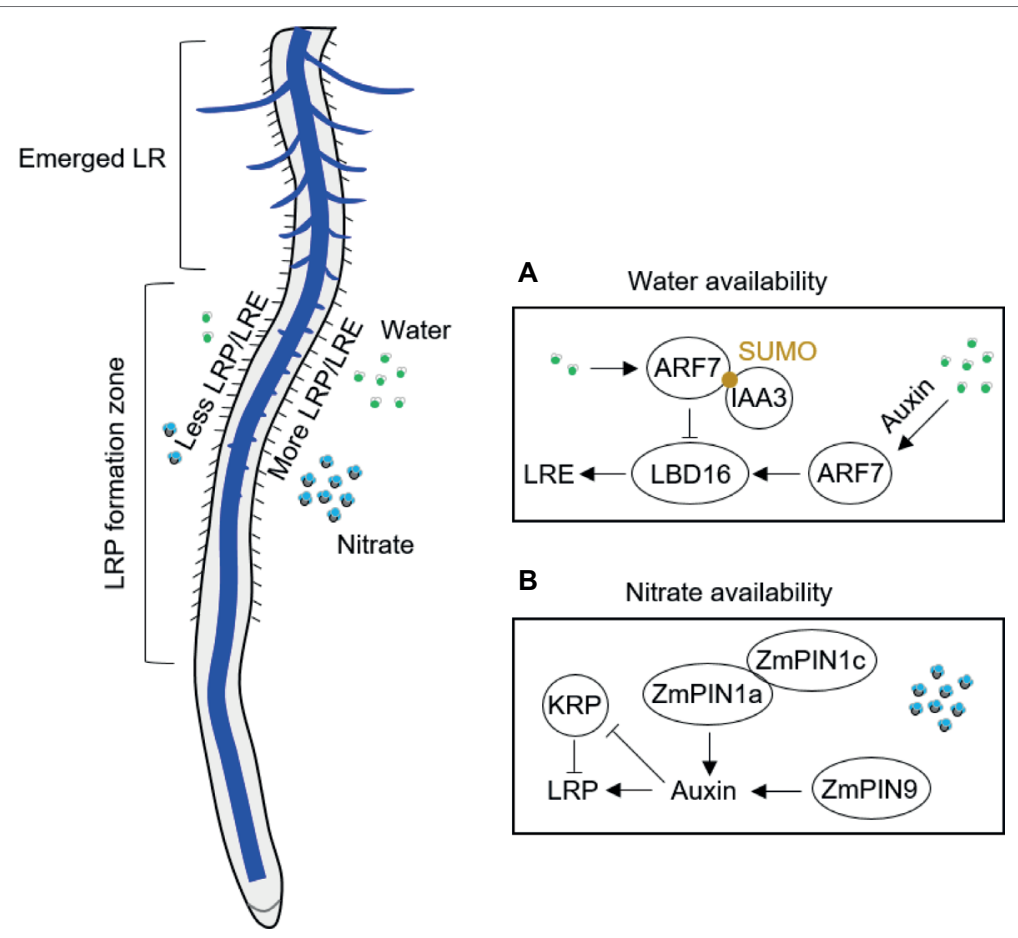

B

Nitrate availability

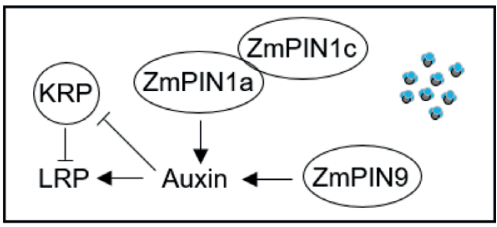

FIGURE 1 | Schematic illustration of lateral root branching response to availability of water in $A$. thaliana (A) and of nitrate in maize (B). ARF, auxin response factor; IAA3, Aux/IAA3 (Aux/indole-3-acetic acid protein 3); KRP, Kip-related protein; LBD, LATERAL ORGAN BOUNDARIES (LOB) domain; LR, lateral root; LRE, lateral root emergence; LRP, lateral root primordia; PIN, PIN-Formed; SUMO, small ubiquitin-like modifier.

that localized nitrate mainly induced lateral root formation but little effects on the density of lateral roots in both hydroponics (Liu et al., 2010) and rhizoslides (Dina in't Zandt et al., 2015). This is further validated by a microarray analysis of pericycle cells indicating common mechanisms for lateral root initiation in maize primary and crown roots (Jansen et al., 2013). Different responses on lateral root branching between barley and maize can be explained by species-specific responses to nitrate but also by different developmental stages of root types surveyed in these plant species. Thus, lateral root specific responses to local nitrate depend on the developmental stage when certain root type is formed. For instance, shoot-borne roots specifically initiated during silking form more lateral roots in response to localized nitrate supply than other root types including the shootborne roots formed before silking (Yu et al., 2015, 2016b). This divergent finding can be explained by the higher shoot demand for nutrients during and after silking (Yu et al., 2014b) but also the possibility of specific hormone signaling from the reproductive process (Yu et al., 2016b). For example, basipetal auxin transport is facilitated by ZmPIN1a and ZmPIN1c in response to local nitrate supply (Yu et al., 2016b; Figure 1B). Moreover, monocot-specific PIN9 gene in phloem pole cells of shoot-borne roots at silking modulates auxin efflux to pericycle cells and subsequent cell cycle activation by alleviating the inhibition of Kip-related proteins (KRP) coding genes in maize (Yu et al., 2016b; Figure 1B). Moreover, CPP-like (cysteine-rich polycomb-like) transcription factors have been found specifically enriched in brace roots of maize, which may play an important role in development of reproductive organs and control of cell division in plants (Yu et al., 2016b). It would be interesting to compare the responses of different root types to local nitrogen supply at the flowering stage in order to answer whether in maize this divergent response is root type specific and/or developmental stage dependent.

A study with $A$. thaliana mutants with reduced number of lateral roots indicate that complex architecture and branching pattern of lateral roots are mainly required for the acquisition of immobile resources, such as phosphate, whereas mobile ions like nitrate can be effectively taken up even by restricted root systems (Fitter et al., 2002). This raises the hypothesis that root proliferation in nutrient-rich patches could be more important for the enhanced capture of immobile than mobile ions. In fact, field studies have suggested that enhanced root proliferation in nutrient-rich patches of ammonium and phosphate during seedling stage and adult development is essential for improving phosphate uptake and ultimately grain yield (Jing et al., 2010; Li et al., 2012, 2016; Ma et al., 2013). One possible explanation for this observation could be indirect effects of solubilization of mineral phosphate by rhizosphere acidification using ammonium fertilization. Alternatively, fine lateral root proliferation substantially increases exudate secretion to the rhizosphere, which can be used as the carbon source for beneficial interactions of the microbiome at the rootsoil interface. 


\section{ROOT TYPE-SPECIFIC BRANCHING PATTERNS}

Recent experiments highlight root type-specific transcriptomic, anatomical, and physiological differences in maize (Tai et al., 2015; Ahmed et al., 2018). Distinct root types of maize show diverse branching responses to nitrate and also host different fungal taxa in their axial and lateral roots (Yu et al., 2016b, 2018). A novel phenotyping approach demonstrates distinct growth rates of three types of lateral roots contribution to the random patterning of lateral root formation in pearl millet and maize (Passot et al., 2018). This phenomenon raises the question whether lateral root types with divergent lengths show distinct competences of their corresponding pericycle cells for dividing. To further study this question, diverse inbred lines with natural variation for lateral root patterning and spacing could be studied in maize.

\section{CONCLUSIONS AND PERSPECTIVES}

Lateral root branching of maize plants grown in soil is root type specific and depends on hormonal crosstalk and signal transduction based on local sensing of water and nutrients. Nevertheless, these molecular processes have not been understood in full detail at the cellular level. Therefore, systemic cell-type-specific analyses in different root types will be instrumental to clarify the identity of pericycle and endodermis cells in maize in response to local water and

\section{REFERENCES}

Ahmed, M. A., Zarebanadkouki, M., Kaestner, A., and Carminati, A. (2016). Measurements of water uptake of maize roots: the key function of lateral roots. Plant Soil 398, 59-77. doi: 10.1007/s11104-015-2639-6

Ahmed, M. A., Zarebanadkouki, M., Meunier, F., Javaux, M., Kaestner, A., and Carminati, A. (2018). Root type matters: measurement of water uptake by seminal, crown, and lateral roots in maize. J. Exp. Bot. 69, 1199-1206. doi: $10.1093 / \mathrm{jxb} / \mathrm{erx} 439$

Atkinson, J. A., Rasmussen, A., Traini, R., Voß, U., Sturrock, C. J., Mooney, S. J., et al. (2014). Branching out in roots: uncovering form, function and regulation. Plant Physiol. 178, 538-550. doi: 10.1104/pp.114.245423

Bao, Y., Aggarwal, P., Robbins, N. E., Sturrock, C. J., Thompson, M. C., Tan, H. Q., et al. (2014). Plant roots use a patterning mechanism to position lateral root branches toward available water. Proc. Natl. Acad. Sci. USA 111, 9319-9324. doi: 10.1073/pnas.1400966111

Burton, A. L., Brown, K. M., and Lynch, J. P. (2013). Phenotypic diversity of root anatomical and architectural traits in Zea species. Crop Sci. 53, 1042-1055. doi: 10.2135/cropsci2012.07.0440

Chen, Y., Xie, Y., Song, C., Zheng, L., Rong, X., Jia, L., et al. (2018). A comparison of lateral root patterning among dicot and monocot plants. Plant Sci. 274, 201-211. doi: 10.1016/j.plantsci.2018.05.018

Dina in't Zandt, D., Le Marie, C., Kirchgessner, N., Visser, E. J., and Hund, A. (2015). High-resolution quantification of root dynamics in split-nutrient rhizoslides reveals rapid and strong proliferation of maize roots in response to local high nitrogen. J. Exp. Bot. 66, 5507-5517. doi: 10.1093/ jxb/erv307

Drew, M. C., Saker, L. R., and Ashley, T. W. (1973). Nutrient supply and the growth of the seminal root system in barley: I. The effect of nitrate concentration on the growth of axes and laterals. J. Exp. Bot. 24, 1189-1202. doi: $10.1093 / \mathrm{jxb} / 24.6 .1189$ nutrient supply (Kortz et al., 2019). In particular, root type has to be considered when studying the mechanism of lateral root formation as maize has a unique architectural pattern in comparison to the other crop species (Burton et al., 2013; Tai et al., 2015; Yu et al., 2016a). Signal transduction induced by water and nutrients at the rootsoil interface needs to be explored in large genetic populations on the molecular level and by advanced in situ imaging (van Dusschoten et al., 2016; Tardieu et al., 2017). To this end, understanding the reprogramming of lateral root formation and architectural plasticity in response to water and nutrient availability in the context of yield acquisition and resource use efficiency can be relevant for rational breeding approaches.

\section{AUTHOR CONTRIBUTIONS}

PY, FH and CL contributed to the writing of this minireview.

\section{FUNDING}

Root research in CL's laboratory is supported by the National Natural Science Foundation of China (no. 31272232). FH is funded by the Deutsche Forschungsgemeinschaft (DFG) grant no. HO2249/12-1 and the Bundesministerium für Bildung und Forschung (BMBF) grant no. 031-B0195C. PY's work on lateral roots in maize is funded by DFG grant no. YU 272/1-1.

Fitter, A., Williamson, L., Linkohr, B., and Leyser, O. (2002). Root system architecture determines fitness in an Arabidopsis mutant in competition for immobile phosphate ions but not for nitrate ions. Proc. R. Soc. Lond. B Biol. Sci. 269, 2017-2022. doi: 10.1098/rspb.2002.2120

Giehl, R. F., and von Wirén, N. (2018). Hydropatterning-how roots test the waters. Science 362, 1358-1359. doi: 10.1126/science.aav9375

Guo, Y., Chen, F., Zhang, F., and Mi, G. (2005). Auxin transport from shoot to root is involved in the response of lateral root growth to localized supply of nitrate in maize. Plant Sci. 169, 894-900. doi: 10.1016/j. plantsci.2005.06.007

Hackett, C. (1972). A method of applying nutrients locally to roots under controlled conditions, and some morphological effects of locally applied nitrate on the branching of wheat roots. Aust. J. Biol. Sci. 25, 1169-1180. doi: 10.1071/BI9721169

Hochholdinger, F., Yu, P., and Marcon, C. (2017). Genetic control of root system development in maize. Trends Plant Sci. 23, 79-88. doi: 10.1016/j. tplants.2017.10.004

Huang, S., Chen, S., Liang, Z., Zhang, C., Yan, M., Chen, J., et al. (2015). Knockdown of the partner protein OsNAR2.1 for high-affinity nitrate transport represses lateral root formation in a nitrate-dependent manner. Sci. Rep. 5:18192. doi: $10.1038 /$ srep 18192

Hund, A., Ruta, N., and Liedgens, M. (2009). Rooting depth and water use efficiency of tropical maize inbred lines, differing in drought tolerance. Plant Soil 318, 311-325. doi: 10.1007/s11104-008-9843-6

Jansen, L., Hollunder, J., Roberts, I., Forestan, C., Fonteyne, P., Van Quickenborne, C., et al. (2013). Comparative transcriptomics as a tool for the identification of root branching genes in maize. Plant Biotechnol. J. 11, 1092-1102. doi: 10.1111/pbi.12104

Jia, X., Liu, P., and Lynch, J. P. (2018). Greater lateral root branching density in maize improves phosphorus acquisition from low phosphorus soil. J. Exp. Bot. 69, 4961-4970. doi: 10.1093/jxb/ery252 
Jing, J., Rui, Y., Zhang, F., Rengel, Z., and Shen, J. (2010). Localized application of phosphorus and ammonium improves growth of maize seedlings by stimulating root proliferation and rhizosphere acidification. Field Crops Res. 119, 355-364. doi: 10.1016/j.fcr.2012.04.009

Kortz, A., Hochholdinger, F., and Yu, P. (2019). Cell type-specific transcriptomics of lateral root formation and plasticity. Front. Plant Sci. 10:21. doi: 10.3389/ fpls.2019.00021

Li, H., Wang, X., Rengel, Z., Ma, Q., Zhang, F., and Shen, J. (2016). Root over-production in heterogeneous nutrient environment has no negative effects on Zea mays shoot growth in the field. Plant Soil 409, 405-417. doi: $10.1007 / \mathrm{s} 11104$

Li, H., Zhang, F., and Shen, J. (2012). Contribution of root proliferation in nutrient-rich soil patches to nutrient uptake and growth of maize. Pedosphere 22, 776-784. doi: 10.1016/S1002-0160(12)60063-0

Liu, J., An, X., Cheng, L., Chen, F., Bao, J., Yuan, L., et al. (2010). Auxin transport in maize roots in response to localized nitrate supply. Ann. Bot. 106, 1019-1026. doi: 10.1093/aob/mcq202

Liu, J., Han, L., Chen, F., Bao, J., Zhang, F., and Mi, G. (2008). Microarray analysis reveals early responsive genes possibly involved in localized nitrate stimulation of lateral root development in maize (Zea mays L.). Plant Sci. 175, 272-282. doi: 10.1016/j.plantsci.2008.04.009

Liu, Y., Donner, E., Lombi, E., Li, R. Y., Wu, Z. C., Zhao, F. J., et al. (2013). Assessing the contributions of lateral roots to element uptake in rice using an auxin-related lateral root mutant. Plant Soil 372, 125-136. doi: 10.1007/ s11104-012-1582-Z

Lynch, J. P. (2013). Steep, cheap and deep: an ideotype to optimize water and $\mathrm{N}$ acquisition by maize root systems. Ann. Bot. 112, 347-357. doi: 10.1093/ aob/mcs 293

Lynch, J. P. (2015). Root phenes that reduce the metabolic costs of soil exploration: opportunities for 21st century agriculture. Plant Cell Environ. 38, 1775-1784. doi: $10.1111 /$ pce. 12451

Lynch, J. P., Chimungu, J. G., and Brown, K. M. (2014). Root anatomical phenes associated with water acquisition from drying soil: targets for crop improvement. J. Exp. Bot. 65, 6155-6166. doi: 10.1093/jxb/eru162

Ma, Q., Zhang, F., Rengel, Z., and Shen, J. (2013). Localized application of $\mathrm{NH}_{4}{ }^{+}-\mathrm{N}$ plus $\mathrm{P}$ at the seedling and later growth stages enhances nutrient uptake and maize yield by inducing lateral root proliferation. Plant Soil 372, 65-80. doi: 10.1007/s11104-013-1735-8

Möller, B. K., Xuan, W., and Beeckman, T. (2017). Dynamic control of lateral root positioning. Curr. Opin. Plant Biol. 35, 1-7. doi: 10.1016/j.pbi.2016.09.001

Orman-Ligeza, B., Morris, E. C., Parizot, B., Lavigne, T., Babé, A., Ligeza, A., et al. (2018). The xerobranching response represses lateral root formation when roots are not in contact with water. Curr. Biol. 28, 3165-3173. doi: 10.1016/j.cub.2018.07.074

Orosa-Puente, B., Leftley, N., von Wangenheim, D., Banda, J., Srivastava, A. K., Hill, K., et al. (2018). Root branching toward water involves posttranslational modification of transcription factor ARF7. Science 362, 1407-1410. doi: $10.1126 /$ science.aau3956

Ötvös, K., and Benková, E. (2017). Spatiotemporal mechanisms of root branching. Curr. Opin. Genet. Dev. 45, 82-89. doi: 10.1016/j.gde.2017.03.010

Passot, S., Moreno-Ortega, B., Moukouanga, D., Balsera, C., Guyomarc'h, S., Lucas, M., et al. (2018). A new phenotyping pipeline reveals three types of lateral roots and a random branching pattern in two cereals. Plant Physiol. 177, 896-910. doi: 10.1104/pp.17.01648

Postma, J. A., Dathe, A., and Lynch, J. P. (2014). The optimal lateral root branching density for maize depends on nitrogen and phosphorus availability. Plant Physiol. 166, 590-602. doi: 10.1104/pp.113.233916

Robbins, N. E., and Dinneny, J. R. (2015). The divining root: moisture-driven responses of roots at the micro-and macro-scale. J. Exp. Bot. 66, 2145-2154. doi: $10.1093 / \mathrm{jxb} / \mathrm{eru} 496$

Robbins, N. E., and Dinneny, J. R. (2018). Growth is required for perception of water availability to pattern root branches in plants. Proc. Natl. Acad. Sci. USA 115, 822-831. doi: 10.1073/pnas.1710709115
Robinson, D. (1994). The responses of plants to non-uniform supplies of nutrients. New Phytol. 127, 635-674. doi: 10.1111/j.1469-8137.1994. tb02969.x

Rogers, E. D., and Benfey, P. N. (2015). Regulation of plant root system architecture: implications for crop advancement. Curr. Opin. Biotechnol. 32, 93-98. doi: 10.1016/j.copbio.2014.11.015

Sun, C. H., Yu, J. Q., and Hu, D. G. (2017). Nitrate: a crucial signal during lateral roots development. Front. Plant Sci. 8:485. doi: 10.3389/fpls.2017.00485

Tai, H., Lu, X., Opitz, N., Marcon, C., Paschold, A., Lithio, A., et al. (2015). Transcriptomic and anatomical complexity of primary, seminal, and crown roots highlight root type-specific functional diversity in maize (Zea mays L.). J. Exp. Bot. 67, 1123-1135. doi: 10.1093/jxb/erv513

Tardieu, F., Cabrera-Bosquet, L., Pridmore, T., and Bennett, M. (2017). Plant phenomics, from sensors to knowledge. Curr. Biol. 27, 770-783. doi: 10.1016/j. cub.2017.05.055

van Dusschoten, D., Metzner, R., Kochs, J., Postma, J. A., Pflugfelder, D., Buehler, J., et al. (2016). Quantitative 3D analysis of plant roots growing in soil using magnetic resonance imaging. Plant Physiol. 170, 1176-1188. doi: $10.1104 /$ pp.15.01388

Wang, Y., Mi, G., Chen, F., Zhang, J., and Zhang, F. (2004). Response of root morphology to nitrate supply and its contribution to nitrogen accumulation in maize. J. Plant Nutr. 27, 2189-2202. doi: 10.1081/PLN-200034683

Yu, P., Baldauf, J., Lithio, A., Marcon, C., Nettleton, D., Li, C., et al. (2016b). Root type specific reprogramming of maize pericycle transcriptomes by local high nitrate results in disparate lateral root branching patterns. Plant Physiol. 170, 1783-1798. doi: 10.1104/pp.15.01885

Yu, P., Eggert, K., von Wirén, N., Li, C., and Hochholdinger, F. (2015). Celltype specific gene expression analyses by RNA-Seq reveal local high nitrate triggered lateral root initiation in shoot-borne roots of maize by modulating auxin-related cell cycle-regulation. Plant Physiol. 169, 690-704. doi: 10.1104/ pp.15.00888

Yu, P., Gutjahr, C., Li, C., and Hochholdinger, F. (2016a). Genetic control of lateral root formation in cereals. Trends Plant Sci. 21, 951-961. doi: 10.1016/j. tplants.2016.07.011

Yu, P., Li, X., Yuan, L., and Li, C. (2014b). A novel morphological response of maize (Zea mays) adult roots to heterogeneous nitrate supply revealed by a split-root experiment. Physiol. Plant. 150, 133-144. doi: 10.1111/ ppl.12075

Yu, P., Wang, C., Baldauf, J. A., Tai, H., Gutjahr, C., Hochholdinger, F., et al. (2018). Root type and soil phosphate determine the taxonomic landscape of colonizing fungi and the transcriptome of field-grown maize roots. New Phytol. 217, 1240-1253. doi: 10.1111/nph.14893

Yu, P., White, P., Hochholdinger, F., and Li, C. (2014a). Phenotypic plasticity of the maize root system in response to heterogeneous nitrogen availability. Planta 240, 667-678. doi: 10.1007/s00425-014-2150-y

Zhan, A., and Lynch, J. P. (2015). Reduced frequency of lateral root branching improves $\mathrm{N}$ capture from low-N soils in maize. J. Exp. Bot. 66, 2055-2065. doi: 10.1093/jxb/erv007

Zhan, A., Schneider, H., and Lynch, J. (2015). Reduced lateral root branching density improves drought tolerance in maize. Plant Physiol. 168, 1603-1615. doi: $10.1104 / \mathrm{pp} .15 .00187$

Conflict of Interest Statement: The authors declare that the research was conducted in the absence of any commercial or financial relationships that could be construed as a potential conflict of interest.

Copyright (c) $2019 \mathrm{Yu}$, Hochholdinger and Li. This is an open-access article distributed under the terms of the Creative Commons Attribution License (CC BY). The use, distribution or reproduction in other forums is permitted, provided the original author(s) and the copyright owner(s) are credited and that the original publication in this journal is cited, in accordance with accepted academic practice. No use, distribution or reproduction is permitted which does not comply with these terms. 